\title{
Importancia de los análisis serológicos, moleculares y virológicos en la vigilancia de la fiebre amarilla en Colombia, 2006-2008
}

\author{
Gloria Inés Múnera, Jairo Andrés Méndez, Gloria Janneth Rey \\ Grupo de Virología, Instituto Nacional de Salud, Bogotá, D.C., Colombia
}

\begin{abstract}
Introducción. La fiebre amarilla es una fiebre hemorrágica viral inmunoprevenible que continúa causando importante morbilidad y mortalidad en regiones tropicales y subtropicales. En Colombia hay aproximadamente cinco millones de personas en riesgo de adquirir la infección.

Objetivo. Describir la importancia de los análisis serológicos, moleculares y virológicos en la vigilancia de la fiebre amarilla en Colombia, con base en los resultados obtenidos de muestras recibidas en el Laboratorio de Arbovirus del Grupo de Virología del Instituto Nacional de Salud, entre 2006 y 2008 , y recalcar la relevancia de una oportuna y adecuada recolección de muestras para la confirmación de casos.

Materiales y métodos. Se procesaron 2.096 muestras de suero y tejidos utilizando las pruebas ELISA para IgM contra fiebre amarilla, aislamiento viral-inmunofluorescencia indirecta y transcriptasa inversareacción en cadena de la polimerasa. Las muestras positivas se correlacionaron con los hallazgos clínicos y epidemiológicos para su interpretación y confirmación.

Resultados. El $82 \%$ de los casos confirmados por histopatología en este período también se confirmaron en nuestro laboratorio por técnicas serológicas y moleculares; estos casos provenían de zonas selváticas y del piedemonte de la Cordillera Oriental.

Conclusión. Se observa la necesidad de seguir manteniendo y fortaleciendo los procesos de vigilancia en las regiones de mayor circulación del virus, para la captación oportuna de casos. Se recalca la importancia del diagnóstico por medio de las técnicas descritas, las cuales se pueden realizar en muestras de pacientes vivos, contrario a las pruebas histopatológicas que requieren muestras de casos fatales.
\end{abstract}

Palabras clave: arbovirus, fiebre amarilla, vigilancia epidemiológica, prueba ELISA, reacción en cadena de la polimerasa de transcriptasa inversa, análisis virológico, Colombia.

Serological, molecular and virological analyses associated with yellow fever surveillance in Colombia

Introduction. Yellow fever is an immunopreventable viral hemorrhagic fever that causes high morbidity and mortality in tropical and sub-tropical regions. In Colombia, approximately 5 million persons are at risk of becoming infected with yellow fever virus.

Objective. The serological, molecular and virological analyses on the yellow fever surveillance samples were summarized in order to indicate the importance of appropriate and timely sampling in the process of case confirmation.

Materials and methods. The survey was based on samples received at the Arbovirus Laboratory, Virology Group, Instituto Nacional de Salud, Bogotá, during years 2006 to 2008. A total of 2,096 serum and tissue samples were tested for IgM antibodies against yellow fever by capture enzymelinked immunosorbent assay, viral isolation-indirect fluorescence antibody technique, and reverse transcriptase-polymerase chain reaction. Positive samples were correlated with the clinical and epidemiological findings for their interpretation and confirmation.

Results. Of the 15 yellow fever cases confirmed in Colombia during 2006-2008 by histopathological techniques, $82 \%$ were confirmed at the Arbovirus Laboratory using serologic and molecular techniques. The positive cases were distributed in the rainforest region and in the foothills of the eastern chain of the Andes mountains.

Conclusion. The case distribution and prognosis illustrated the necessity of maintaining and strengthening the surveillance processes in those regions where the yellow fever virus is circulating. The cases must be recruited and diagnosed sufficiently early in order to use the above techniques in samples from live patients, in contrast to the histopathological procedures that require samples from fatal cases.

Key words: arboviruses, yellow fever, epidemiologic surveillance, enzyme-linked immunosorbent assay, reverse transcriptase polymerase chain reaction, virological analysis, Colombia. 
La fiebre amarilla es una fiebre hemorrágica viral que representa una importante causa de morbimortalidad en regiones tropicales y subtropicales principalmente de Suramérica y África, cuya verdadera incidencia se cree que sea 5 a 10 veces mayor que la reportada oficialmente (1-4).

En Colombia existen, aproximadamente, cinco millones de personas en riesgo de contraer la infección por el simple hecho de vivir en zonas cercanas a territorios selváticos y en el piedemonte de las Cordilleras Central y Oriental, así como en la cuenca de los ríos Magdalena, Orinoco, Atrato, Catatumbo y Amazonas, y en las estribaciones de la Sierra Nevada de Santa Marta y la Serranía del Perijá (5).

El virus de la fiebre amarilla se logró aislar a comienzos del siglo $\mathrm{XX}$ de la sangre de un joven de Ghana llamado Asibi, convirtiéndose desde entonces en la cepa de referencia $(1,6)$. Este virus es el prototipo del género Flavivirus (familia flaviviridae), tiene $45 \mathrm{~nm}$ de diámetro y está constituido por una cadena sencilla de ARN de polaridad positiva. Posee tres proteínas estructurales que presentan la mayor parte de los epítopos contra los cuales se genera la respuesta inmunitaria, la cual generalmente es de anticuerpos protectores y neutralizadores $(1,7)$; sus proteínas no estructurales están implicadas principalmente en el proceso de replicación, en la activación de la vía alterna del complemento y en el ataque por células T citotóxicas.

La enfermedad puede ser asintomática o presentarse con fiebre moderada o como una fiebre hemorrágica fatal $(1,2)$.

La fiebre amarilla selvática es una zoonosis cuyos vectores pueden ser los mosquitos Hemagogus jantinomys o Sabethes spp., y los reservorios pueden ser diferentes especies de primates, los cuales también sufren la enfermedad. La fiebre amarilla urbana es una antroponosis, en la cual Aedes aegypti es el vector.

Es difícil realizar un diagnóstico rápido y acertado de la enfermedad, ya que se puede confundir con

\section{Correspondencia:}

Gloria Inés Múnera, Grupo de Virología, Instituto Nacional de Salud, Avenida Calle 26 № 51-20, Bogotá, D.C., Colombia. Teléfono: (571) 220 7700, extensión 1426; fax: (571) 2207700 , extensión 1428

gloriaim@yahoo.com

Recibido: 13/11/09; aceptado:07/04/10 la hepatitis viral fulminante beta-delta (7), con otras fiebres hemorrágicas producidas por arbovirus (dengue) o por arenavirus, con malaria producida por Plasmodium falciparum, con leptospirosis, fiebre tifoidea, rickettsiosis y con hepatotoxicidad por medicamentos y agentes tóxicos (1).

Durante la fase temprana de la enfermedad (primeros cuatro días) es posible la detección del ácido ribonucleico (ARN) viral en muestras de suero para un diagnóstico rápido, preciso y eficiente (8-12) por la técnica de la transcriptasa inversa-reacción en cadena de la polimerasa de (RT-PCR). En esta misma fase es posible hacer el análisis virológico intentando el aislamiento del virus en suero, cultivándolo en células AA C6/36 (clon obtenido del mosquito Aedes albopictus) 0 inoculándolo en el cerebro de ratones lactantes (13-16) e identificando posteriormente el antígeno viral por la técnica de inmunofluorescencia indirecta (IFI) $(16,17)$. Éste es un procedimiento prolongado cuyos resultados se obtienen dos semanas después de iniciado el cultivo de las células.

Por otra parte, a los 5 a 7 días de la aparición de los síntomas y hasta los 2 a 3 meses, se pueden detectar anticuerpos tipo IgM en suero por medio de ELISA de captura (MAC-ELISA) $(13-15$, 1821). Existen otras pruebas serológicas para la detección de anticuerpos que son más complejas y que requieren sueros pareados para confirmar el diagnóstico (7).

La fiebre amarilla es un evento en control internacional y el objetivo general de su vigilancia es hacer el seguimiento continuo y sistemático de los casos de acuerdo con los procesos establecidos para la notificación, recolección y análisis de datos, que conduzcan finalmente a la prevención y el control de la enfermedad. El diagnóstico de los casos se hace definiendo inicialmente los casos probables y confirmándolos por medio del laboratorio. Los casos confirmados se reportan al SIVIGILA (Sistema Nacional de Vigilancia en Salud Pública), el cual recopila toda la información semanal de los casos de interés en salud pública provenientes de todo el país, para su continua vigilancia y control.

El presente estudio describe el comportamiento de la vigilancia de la fiebre amarilla por el laboratorio en Colombia, de acuerdo con los resultados obtenidos de las muestras sospechosas recibidas en el Laboratorio de Arbovirus del Grupo de Virología del Instituto Nacional de Salud de Colombia, entre 2006 y 2008. 


\section{Materiales y métodos}

\section{Muestra de estudio}

Se analizaron 2.096 muestras de casos sospechosos de fiebre amarilla procedentes de 18 Laboratorios de Salud Pública Departamentales; de éstas, 1.346 correspondían a pacientes con menos de cinco días de evolución, 678 pertenecían a pacientes con más de cinco días de evolución, 20 fueron recolectadas entre los días 4 y 6 , y las 52 restantes eran de pacientes cuyas fichas epidemiológicas no tenían la información de los días de evolución de la enfermedad (cuadro 1).

\section{Análisis virológico: aislamiento viral- inmunofuorescencia indirecta}

Se realizó en 1.299 muestras de pacientes con menos de cinco días de evolución, en 2 muestras con 4 a 6 días de evolución y en 52 muestras sin esta información (cuadro 1).

Cada suero diluido 1:10 con Minimum Essential Medium (MEM-Sigma) fue sembrado en tubos de cultivo con una monocapa de células AA C6/36 de 24 horas de subcultivo. Los cultivos inoculados se incubaron a $28{ }^{\circ} \mathrm{C}$ por 10 días, observando diariamente su evolución en microscopio invertido y registrando cualquier cambio o alteración morfológica que presentaran las células (efecto citopático). Al cabo de este tiempo se cosecharon las células de cada tubo, se sembraron en láminas de 18 pozos (Cell-Line/Erie Scientific Co.), se fijaron en acetona a $-20{ }^{\circ} \mathrm{C}$, y se realizó posteriormente la técnica de inmunofluorescencia indirecta (IFI), utilizando inicialmente un anticuerpo policlonal anti-Flavivirus (líquido ascítico inmune,
$\mathrm{LAI}$ ) y revelando la reacción con una lgG anti-ratón producida en cabra y conjugada con isotiocianato de fluoresceína (ICN/CAPPEL).

Las muestras positivas para Flavivirus en esta reacción se procesaron posteriormente con anticuerpos monoclonales contra fiebre amarilla y contra los serotipos de dengue 1 (HAW, B82472), dengue 2 (New Guinea C, B82473), dengue 3 (H87, B29806), dengue 4 (H241, B82475) (CDC Puerto Rico), para determinar la presencia del virus de la fiebre amarilla o el serotipo del virus de dengue infectivo.

Para la lectura se tuvo en cuenta el grado de fluorescencia ( 0 a 4 ) de acuerdo con los siguientes criterios descritos en el método de ensayo (MEN) de IFI para dengue y fiebre amarilla del Grupo de Virología del Instituto Nacional de Salud (MEN-R01.003.5100-022): 0, en ausencia de fluorescencia (células totalmente rojas); 1, cuando se observa fluorescencia en el $10 \%$ de las células; 2 , con fluorescencia en $25 \%$ de las células; 3 , con fluorescencia en $50 \%$ de las células, y 4 , con fluorescencia en más de $50 \%$ de las células. Las muestras cuya fluorescencia fue 0 se consideraron negativas. Las muestras cuya fluorescencia fue 1 , se consideraron dudosas y a éstas se les realizó un pase, recurriendo al sobrenadante del cultivo. Las muestras cuyo grado de fluorescencia fue igual a 2 o mayor se consideraron positivas.

\section{Análisis serológico: detección de anticuerpos IgM contra fiebre amarilla por MAC-ELISA}

Se realizó en 678 muestras de pacientes con más de cinco días de evolución, en 15 muestras con 4 a 6 días y en 52 muestras sin información. Se

Cuadro 1. Distribución de las muestras procesadas según la técnica utilizada para el diagnóstico y vigilancia de la fiebre amarilla en Colombia, 2006-2008.

\begin{tabular}{|c|c|c|c|c|c|c|c|}
\hline Técnica & Muestra & $\begin{array}{l}\text { Días de } \\
\text { evolución }\end{array}$ & $\begin{array}{l}\text { Muestra } \\
2006\end{array}$ & $\begin{array}{l}\text { Muestras } \\
2007\end{array}$ & $\begin{array}{l}\text { Muestras } \\
2008\end{array}$ & $\begin{array}{c}\text { Total } \\
\text { muestras } \\
\text { 2006-2008 }\end{array}$ & $\begin{array}{c}\text { Total } \\
\text { muestras } \\
\text { positivas }\end{array}$ \\
\hline Aislamiento viral & Suero & $\leq 5$ & 427 & 463 & 409 & 1.299 & 0 \\
\hline RT-PCR & Tejidos & $\leq 5$ & 16 & 19 & 12 & 47 & 4 \\
\hline MAC-ELISA & Suero & $\geq 5$ & 265 & 196 & 217 & 678 & 4 \\
\hline Aislamiento viral y & & & & & & & \\
\hline MAC-ELISA & Suero & Sin dato & 18 & 28 & 6 & 52 & 0 \\
\hline RT-PCR y MAC-ELISA & Suero-tejido & 4 a 6 & 3 & 7 & 3 & 13 & 1 \\
\hline $\begin{array}{l}\text { RT-PCR, aislamiento } \\
\text { viral y MAC-ELISA }\end{array}$ & Suero & 4 a 6 & 0 & 1 & 1 & 2 & 0 \\
\hline $\begin{array}{l}\text { RT-PCR y } \\
\text { aislamiento viral }\end{array}$ & Suero & 4 a 6 & 0 & 5 & 0 & $\begin{array}{r}5 \\
2.096\end{array}$ & $\begin{array}{l}0 \\
9\end{array}$ \\
\hline
\end{tabular}


utilizaron placas de microtitulación de fondo plano (Costar) de 96 pozos sensibilizadas con IgG contra IgM humana producida en cabra (ICN/CAPPEL), incubadas previamente a $4{ }^{\circ} \mathrm{C}$; se lavaron cinco veces con $350 \mu \mathrm{l}$ de solución tampón salina de fosfatos (PBS) más 0,5\% Tween 20 (PBSTween) por pozo, se dispensaron $200 \mu \mathrm{l}$ de leche descremada al 5\% preparada en PBS-Tween para bloquear los sitios inespecíficos, se incubaron a $37^{\circ} \mathrm{C}$ por 30 minutos, se realizaron cinco lavados $\mathrm{y}$, posteriormente, se dispensaron $50 \mu \mathrm{l}$ de las muestras de suero y de los controles positivo y negativo diluidas 1:100 en PBS-Tween en dos pozos consecutivos horizontalmente.

Después de una hora de incubación a $37^{\circ} \mathrm{C}$ y de cinco lavados, se dispensaron $50 \mu \mathrm{l}$ de antígeno normal $(\mathrm{Ag} \mathrm{N})$ producido en el Instituto Nacional de Salud por extracción con acetona-sacarosa de cerebros de ratones lactantes sanos (19) en el primer pozo de cada muestra y $50 \mu \mathrm{l}$ de antígeno viral (Ag V) producido en el Instituto Nacional de Salud por extracción con acetona-sacarosa de cerebros de ratones lactantes inoculados con virus de la fiebre amarilla (19) en el segundo, diluidos 1:100 en PBS-Tween.

Luego de una hora de incubación en cámara húmeda a $37^{\circ} \mathrm{C}$ y de cinco lavados, se agregaron $50 \mu \mathrm{l}$ de anticuerpo monoclonal contra Flavivirus conjugado con peroxidasa (MAB 6B6C-1/HRP - CDC), diluido 1:2.500 en PBS-Tween; se incubaron por una hora en cámara húmeda a $37^{\circ} \mathrm{C}$, se lavaron seis veces y posteriormente se agregaron $50 \mu \mathrm{l}$ de sustrato TMB (3,3',5,5'-tetrametilbenzidina) SIGMA T-2885 $+\mathrm{H}_{2} \mathrm{O}_{2} 3 \%$. Se incubaron a temperatura ambiente por 15 minutos evitando la luz directa hasta que se desarrollara una coloración azul fuerte en el pozo del control positivo más Ag V.

Finalmente, se hizo la lectura de densidad óptica de la microplaca en un Lector MRX (Dynatech) a $450 \mathrm{~nm}$, con filtro de referencia de $630 \mathrm{~nm}$. Para cada muestra se calculó el valor de densidad óptica del pozo con Ag $\mathrm{V}$ menos la densidad óptica del pozo con $\mathrm{Ag} \mathrm{N}$ y el valor de densidad óptica del pozo con $\mathrm{Ag} \mathrm{V}$ dividido por la del pozo con $\mathrm{Ag} \mathrm{N}$, para definir los resultados: positivo, cuando AgV$\mathrm{AgN} \geq 0,150$ y $\mathrm{AgV} / \mathrm{AgN} \geq 3,0$, y negativo, cuando $\mathrm{AgV}-\mathrm{AgN} \leq 0,150$ y $\mathrm{AgV} / \mathrm{AgN} \leq 3,0$. Para hacer el diagnóstico diferencial con dengue, se utilizó el estuche Dengue IgM Capture ELISA, marca PANBIO (Australia), Cat. No. E-DEN01M, teniendo en cuenta las recomendaciones del fabricante.
Análisis molecular: detección de ARN viral por RT-PCR

Se hizo en 47 muestras de tejidos obtenidas por viscerotomía de casos fatales y en 20 muestras de suero con 4 a 6 días de evolución. El ARN extraído de los tejidos y sueros por el método del TrizolLS fue utilizado en una reacción de transcripción inversa utilizando iniciadores específicos para fiebre amarilla, los cuales han demostrado no amplificar para ningún serotipo de virus dengue, bajo las siguientes condiciones: $5 \mu \mathrm{l}$ de tampón 6X para transcripción (New England Biolabs), $3 \mu \mathrm{l}$ de ditiotreitol (DTT) 0,1 M (Sigma), 1,5 $\mu \mathrm{l}$ de cada uno de los desoxinucleótidos trifosfato (dNTP) $10 \mathrm{mM}$ (CPG Inc.), 1,5 $\mu \mathrm{l}$ de transcriptasa inversa M-MLV $200 \mathrm{u} / \mu \mathrm{l}$ (New England Biolabs) y $3 \mu \mathrm{l}$ del iniciador antisentido (JM2751: 5'CCTCTCTGGTAAACATTCT-3') $10 \mu \mathrm{M}$.

La reacción de transcripción inversa se realizó durante una hora a $37{ }^{\circ} \mathrm{C}$ y el ácido desoxirribonucleico complementario (ADNc) generado se utilizó como plantilla en una reacción de PCR, utilizando las siguientes condiciones: $5 \mu \mathrm{l}$ de tampón de PCR 10x (CPG Inc.), $1 \mu \mathrm{l}$ de dNTP (mezcla con $10 \mathrm{mM}$ de cada uno, CPG Inc.), $1 \mu \mathrm{l}$ de iniciador directo

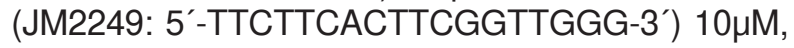
$1 \mu \mathrm{l}$ de iniciador antisentido (JM2673) $10 \mu \mathrm{M}$ y $2,5 \mathrm{U}$ de taq polimerasa (CPG, Inc), en un volumen final de $50 \mu \mathrm{l}$; la reacción se realizó en un termociclador Perkin Elmer con 35 ciclos de desnaturalización $\left(94^{\circ} \mathrm{C}\right)$, hibridación $\left(55^{\circ} \mathrm{C}\right)$ y extensión $\left(72^{\circ} \mathrm{C}\right)$ $(12,22)$.

\section{Resultados}

Entre 2006 y 2008 se procesaron en el Laboratorio de Arbovirus del Grupo de Virología del Instituto Nacional de Salud, en desarrollo de la vigilancia de la fiebre amarilla en Colombia, 2.096 muestras recibidas de los laboratorios de salud pública departamentales.

Teniendo como criterio el número de días de evolución de la enfermedad, se realizaron tres tipos de ensayos diferentes: detección de IgM por MAC-ELISA para el diagnóstico serológico, aislamiento viral-IFI para el diagnóstico virológico y RT-PCR para el diagnóstico molecular; en algunos casos fue necesario hacer más de un ensayo de laboratorio (cuadro 1).

Del total de muestras analizadas, $22(1,05 \%)$ presentaron resultados positivos para fiebre amarilla: 17 por MAC-ELISA (incluyendo 2 muestras de la fase de convalecencia de dos pacientes), 4 por RT-PCR (tejidos y sueros) y una por MAC- 
ELISA y RT-PCR (cuadro 2). No se obtuvo ningún aislamiento viral positivo.

Ocho de las 17 muestras positivas para IgM-FA por MAC-ELISA fueron positivas también para IgM de dengue, lo que hacía sospechar de una reacción cruzada entre flavivirus; en estos casos se confirmó, en efecto, la infección por el virus de dengue (descartando fiebre amarilla) y en 5 de las 9 muestras restantes se descartó igualmente la infección por fiebre amarilla.

Estos resultados se analizaron en reuniones denominadas "unidades de análisis", las cuales se realizan en presencia de los profesionales responsables de la vigilancia epidemiológica y de los laboratorios de Patología, Entomología y Virología del Instituto Nacional de Salud, que conforman el grupo funcional de las enfermedades transmitidas por vectores, en las que se correlacionan los resultados de laboratorio con los hallazgos clínicos y epidemiológicos de los casos probables.

En resumen, se confirmó el diagnóstico de fiebre amarilla en 9 pacientes: 4 por MAC-ELISA, 4 por RT-
PCR y 1 por MAC-ELISA y RT-PCR, provenientes todos de zonas selváticas y del piedemonte de la cordillera oriental (cuadros 1 y 2; figura 1). Por otro lado, y como parte del diagnóstico diferencial, a uno de los pacientes del Guaviare con una muestra en la fase de convalecencia se le diagnosticó malaria por Plasmodium falciparum.

La técnica de RT-PCR mostró una banda única de amplificación del tamaño esperado (502pb) correspondiente a la región de unión de los genes E/NS1 en tres muestras de tejido hepático fresco y un suero de 3 casos fatales (Santander, 2006, Caquetá 2007 y Guaviare 2008) (cuadro 2), y se confirmó por este método el diagnóstico de fiebre amarilla en estos casos. Teniendo en cuenta que los controles de reacción y amplificación no mostraron ninguna banda, es posible descartar una contaminación con fiebre amarilla o con otros flavivirus.

Al comparar los resultados descritos anteriormente con el total de casos de fiebre amarilla confirmados en el SIVIGILA en este período, se pudo observar

Cuadro 2. Procedencia de las muestras positivas para fiebre amarilla en Colombia, 2006-2008, y técnicas diagnósticas utilizadas en el Laboratorio de Virología.

\begin{tabular}{|c|c|c|c|c|c|c|c|c|}
\hline Año & Departamento & Municipio & $\begin{array}{c}\text { Semana } \\
\text { epidemiológica }\end{array}$ & Muestra & $\begin{array}{l}\text { MAC } \\
\text { ELISA }\end{array}$ & $\begin{array}{l}\text { RT } \\
\text { PCR }\end{array}$ & $\begin{array}{c}\lg M \\
\text { dengue }\end{array}$ & $\begin{array}{l}\text { Clasificación } \\
\text { final de caso }\end{array}$ \\
\hline \multirow[t]{10}{*}{2006} & Bolívar & Carmen & 3 & Suero & + & NR & + & Descartado \\
\hline & Vichada & Puerto Carreño & 7 & Suero & + & NR & + & Descartado \\
\hline & Caquetá & Florencia & 17 & Suero & + & NR & - & Confirmado \\
\hline & Putumayo & Puerto Asís & 22 & Suero & + & NR & - & Confirmado \\
\hline & Casanare & Pore & 23 & Suero & + & NR & - & Confirmado \\
\hline & Arauca & Arauquita & 24 & Suero & + & NR & + & Descartado \\
\hline & Atlántico & Baranoa & 26 & Suero & + & NR & + & Descartado \\
\hline & Putumayo & Puerto Asís & 26 & Suero & + & NR & + & Descartado \\
\hline & Guaviare & Miraflores & 34 & Suero & $+{ }^{*}$ & NR & + & Descartado \\
\hline & Guaviare & Miraflores & 35 & Suero & $+* *$ & NR & NR & Descartado \\
\hline \multirow[t]{10}{*}{2007} & Caquetá & Belén & 5 & Tejido & NR & + & NR & Confirmado \\
\hline & Casanare & Yopal & 9 & Tejido & NR & + & NR & Confirmado \\
\hline & Meta & Puerto Gaitán & 20 & Tejido & NR & + & NR & Confirmado \\
\hline & Caquetá & Puerto Rico & 21 & Suero & + & NR & + & Descartado \\
\hline & Vichada & Cumaribo & 22 & Suero & + & NR & + & Descartado \\
\hline & Meta & Vista Hermosa & 24 & Suero & + & NR & NR & Descartado \\
\hline & Caquetá & Puerto Rico & 25 & Suero & + & NR & NR & Confirmado \\
\hline & Meta & Puerto Gaitán & 31 & Suero & $+{ }^{*}$ & NR & - & Descartado \\
\hline & Meta & Puerto Gaitán & 34 & Suero & $+* *$ & NR & NR & Descartado \\
\hline & Bogotá & Clínica Country & 32 & Suero & + & NR & NR & Descartado \\
\hline \multirow[t]{2}{*}{2008} & Guaviare & San José & 2 & Tejido & NR & + & NR & Confirmado \\
\hline & Meta & Puerto Concordia & 51 & Suero-Tejido & + & + & NR & Confirmado \\
\hline
\end{tabular}

*: primera muestra

${ }^{* *}$ : segunda muestra, recolectada en la fase de convalecencia

NR: no se realizó; muestra no apropiada para el procedimiento

+ : resultado positivo

- : resultado negativo 


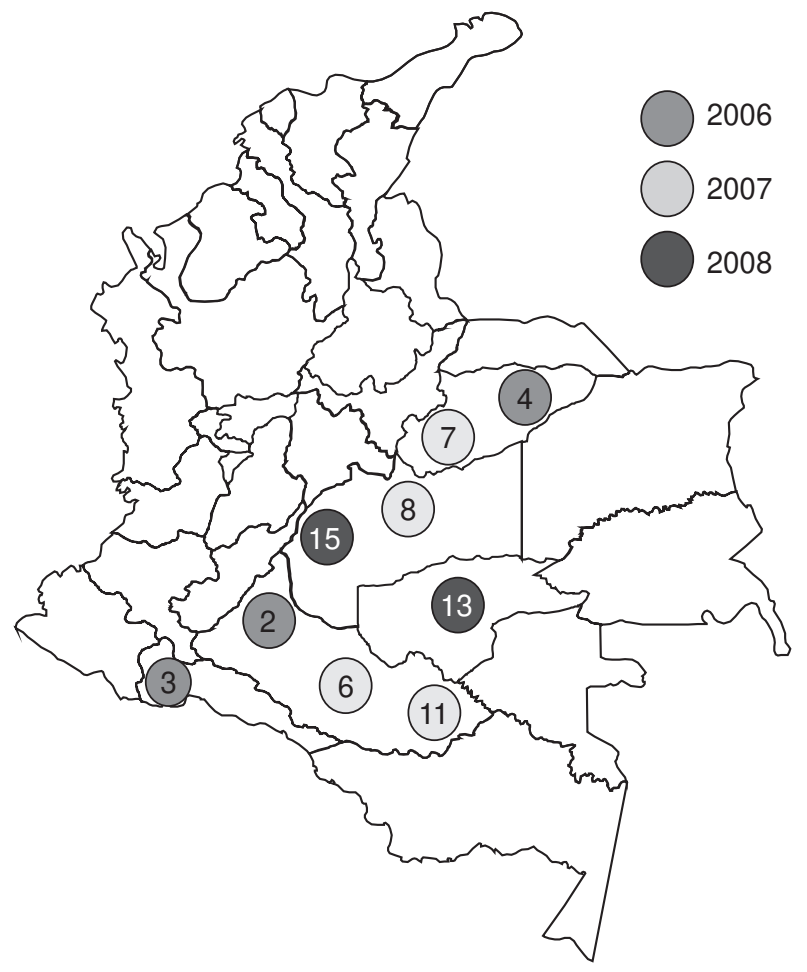

Figura 1. La distribución geográfica de los casos de fiebre amarilla confirmados por el Laboratorio de Virología del Instituto Nacional de Salud entre 2006 y 2008, se mantuvo en zonas selváticas y en el piedemonte de la cordillera oriental. Los números dentro de los círculos indican el número de caso descrito en el cuadro 3. que del total de casos confirmados por el Laboratorio de Patología por medio de técnicas histopatológicas e inmunohistoquímica, 9 de 11 casos (82\%) se confirmaron también en el Laboratorio de Virología. Los dos casos restantes (18\%), uno fue negativo por MAC-ELISA (proveniente del departamento de Vichada) y otro fue negativo por MAC-ELISA y aislamiento viral (proveniente del Guaviare) (cuadro 3). Aunque fueron 15 los casos reportados en SIVIGILA, hubo 4 de los cuales no se recibieron muestras en el Grupo de Virología.

Los 9 casos confirmados de fiebre amarilla presentaban en común varios de los síntomas característicos de la enfermedad, como fiebre, cefalea, mialgias, artralgias, choque, dolor retroocular, vómito negro, melenas, coagulopatías y otras manifestaciones hemorrágicas, ictericia, nefropatía y signos de extravasación, como ascitis, derrame pleural, dolor abdominal e hiperemia conjuntival.

\section{Discusión}

Los ensayos virológicos (aislamiento viral-IFI y RT-PCR) para el diagnóstico de fiebre amarilla son concluyentes, siempre y cuando se utilicen los controles adecuados. De estos ensayos, el aislamiento viral sigue siendo el más utilizado, aunque su éxito, como se observa en este estudio, puede verse afectado por condiciones de la muestra, tales como su estado de conservación

Cuadro 3. Casos de fiebre amarilla confirmados en el Laboratorio de Virología con respecto a los casos confirmados por el Laboratorio de Patología y reportados en el SIVIGILA entre 2006 y 2008 en Colombia.

\begin{tabular}{|c|c|c|c|c|c|c|}
\hline Año & Departamento & $\begin{array}{c}\text { Semana } \\
\text { epidemiológica }\end{array}$ & $\begin{array}{l}\text { Número } \\
\text { de caso }\end{array}$ & $\begin{array}{l}\text { Laboratorio } \\
\text { de Virología }\end{array}$ & $\begin{array}{l}\text { Laboratorio } \\
\text { de Patología }\end{array}$ & SIVIGILA \\
\hline 2006 & $\begin{array}{l}\text { Vichada } \\
\text { Caquetá } \\
\text { Putumayo } \\
\text { Casanare } \\
\text { Norte de Santander }\end{array}$ & $\begin{array}{r}5 \\
17 \\
22 \\
23 \\
37\end{array}$ & $\begin{array}{l}1 \\
2 \\
3 \\
4 \\
5\end{array}$ & $\begin{array}{c}\text { NM } \\
+ \\
+ \\
+ \\
\text { NM }\end{array}$ & $\begin{array}{l}+ \\
+ \\
+ \\
+ \\
+\end{array}$ & $\begin{array}{l}C \\
C \\
C \\
C \\
C\end{array}$ \\
\hline 2007 & $\begin{array}{l}\text { Caquetá } \\
\text { Casanare } \\
\text { Meta } \\
\text { Vichada } \\
\text { Caquetá } \\
\text { Caquetá } \\
\text { Guaviare }\end{array}$ & $\begin{array}{r}5 \\
9 \\
20 \\
20 \\
19 \\
25 \\
48\end{array}$ & $\begin{array}{r}6 \\
7 \\
8 \\
9 \\
10 \\
11 \\
12\end{array}$ & $\begin{array}{c}+ \\
+ \\
+ \\
- \\
\text { NM } \\
+ \\
-\end{array}$ & $\begin{array}{l}+ \\
+ \\
+ \\
+ \\
+ \\
+ \\
+\end{array}$ & $\begin{array}{l}C \\
C \\
C \\
C \\
C \\
C \\
C\end{array}$ \\
\hline 2008 & $\begin{array}{l}\text { Guaviare } \\
\text { Meta } \\
\text { Meta }\end{array}$ & $\begin{array}{r}2 \\
28 \\
51\end{array}$ & $\begin{array}{l}13 \\
14 \\
15\end{array}$ & $\begin{array}{c}+ \\
\mathrm{NM} \\
+\end{array}$ & $\begin{array}{l}+ \\
+ \\
+\end{array}$ & $\begin{array}{l}\mathrm{C} \\
\mathrm{C} \\
\mathrm{C}\end{array}$ \\
\hline
\end{tabular}

C: caso confirmado

NM: muestra no enviada al Laboratorio de Virología

+ : resultado positivo

-: resultado negativo 
y transporte, presencia de detritos tóxicos que alteran las células o una viremia muy baja.

Las técnicas moleculares basadas en la detección del ARN viral ofrecen una alta sensibilidad, lo que facilita la detección incluso de cantidades mínimas de virus, y son, además, $100 \%$ específicas, lo cual facilita el diagnóstico diferencial en áreas endémicas para otros flavivirus; el problema que representan estas técnicas son los costos económicos.

Los ensayos serológicos pueden ser menos específicos, si se considera que detectan anticuerpos contra dos virus tan estrechamente relacionados como el fiebre amarilla y el de dengue, los cuales comparten antígenos estructurales que pueden dificultar el diagnóstico, particularmente, en países donde los dos virus son endémicos. Sin embargo, estos ensayos pueden ser confirmatorios siempre y cuando se acompañen de una historia clínica sugestiva de fiebre amarilla y un antecedente epidemiológico claro, que incluya ausencia de vacunación y procedencia de un área endémica.

Por otra parte, en las zonas endémicas no se debe descartar la posibilidad de infecciones concomitantes con otros microorganismos, como Leptospira spp. o Plasmodium spp. que, además de confundir los resultados, pueden enmascarar la causa real de un evento fatal (23).

Dentro del proceso de vigilancia de fiebre amarilla por el laboratorio es importante realizar una adecuada interpretación de los resultados, correlacionándolos con los datos clínicos y epidemiológicos, teniendo en cuenta que la configuración y confirmación de los casos se realiza de acuerdo con criterios en los cuales el laboratorio ejerce un papel fundamental, ya que se deben cumplir, por lo menos, una de las siguientes condiciones:

a) diagnóstico virológico por aislamiento viral-IFI,

b) diagnóstico molecular por RT-PCR,

c) diagnóstico serológico por MAC-ELISA u otras técnicas que muestren un incremento de títulos en sueros pareados,

d) diagnóstico patológico: hallazgos histopatológicos con necrosis mediozonal o necrosis masiva y estudio inmunohistoquímico que revele presencia de antígenos virales,

e) un individuo asintomático u oligosintomático originado de búsqueda activa sin antecedente vacunal que presente serología (MAC-ELISA) positiva para fiebre amarilla.
Un caso confirmado por nexo epidemiológico corresponde a todo caso probable que fallece antes de 10 días sin confirmación por laboratorio, durante el inicio o curso de un brote en que otro caso ya ha sido confirmado por laboratorio. Un caso descartado es aquel caso probable con diagnóstico por laboratorio negativo o un caso probable con diagnóstico confirmado de otra enfermedad.

El presente estudio demuestra, según los resultados obtenidos entre 2006 y 2008 y la información suministrada al SIVIGILA, que el Laboratorio de Virología, mediante estudios serológicos, moleculares y virológicos, contribuyó a la configuración y confirmación de $82 \%$ de los casos de fiebre amarilla de los cuales recibieron muestras.

$\mathrm{Si}$ bien las técnicas histopatológicas e inmunohistoquímicas fueron confirmatorias en $100 \%$ de los casos, hay que tener en cuenta que todos los casos positivos en este período fueron casos fatales, de los cuales se contaba con tejidos producto de las viscerotomías; en estos casos, el estudio histopatológico por inmunohistoquímica en cortes de hígado constituye una valiosa herramienta diagnóstica $(8,9)$, pero en pacientes vivos, la biopsia hepática para ver los cambios histológicos típicos está absolutamente contraindicada porque se puede generar una hemorragia letal debido a las alteraciones del sistema de coagulación inherentes a la enfermedad, y en estos casos en particular cobran mayor importancia el diagnóstico virológico, el molecular y el serológico.

Finalmente, con este estudio se pone en evidencia que la circulación del virus de la fiebre amarilla en el país se mantiene especialmente en el piedemonte de la Cordillera Oriental y en zonas selváticas, por lo cual es importante fortalecer y mantener los procesos de vigilancia que permitan la identificación y captación de los casos en estas regiones, y la recolección adecuada y oportuna de muestras, ya que la confiabilidad de los resultados de laboratorio depende de la calidad de las muestras y de los cuidados durante su recolección, manipulación y transporte (cadena de frío adecuada), así como del reporte rápido de resultados que permitan la implementación de las medidas de prevención y control de brotes de forma mediata.

\section{Agradecimientos}

Los autores del presente estudio desean agradecer de manera especial a Elizabeth Hunsperger del CDC, Puerto Rico, por su gentil suministro de anticuerpos monoclonales y conjugados; a Diana 
Patricia Rojas, médica epidemióloga del Grupo de Enfermedades Transmitidas por Vectores de la Subdirección de Vigilancia y Control en Salud Pública del Instituto Nacional de Salud por el apoyo e información; a los coordinadores de los Laboratorios de Salud Pública Departamentales del país por el envío de muestras que permiten garantizar la vigilancia de la fiebre amarilla por el laboratorio; a Martha Patricia Velandia, Coordinadora del Grupo PAI del Ministerio de la Protección Social y a Andrés Páez, Ph.D., profesional del Laboratorio de Virología, por sus sugerencias en la revisión del presente manuscrito.

\section{Conflicto de intereses}

Los autores manifiestan que no existe, de manera directa o indirecta, ningún tipo de conflicto de intereses financieros, académicos ni personales para la publicación de este artículo.

\section{Financiación}

Los recursos económicos necesarios para la realización de este trabajo fueron aportados por el Instituto Nacional de Salud de Colombia, a través de la inversión 3606-3-510 3001220 de 2006 y la inversión 3606-3-510 3002 1-11 de 2009, y por el Ministerio de la Protección Social a través del Convenio 239, inversión 3606-3-510- 3002 6-20 de 2008.

\section{Referencias}

1. Monath TP. Yellow fever: an update. Lancet Inf Dis. 2001;1:11-20.

2. Groot H, Boshell J. Dengue, dengue hemorrágico y fiebre amarilla. En: Chalem F, Escandón JE, Campos J, Esguerra R, editores. Medicina interna. Bogotá: Doyma Andina, S.A.; 1992. p.1389-95.

3. Tesh RE. Viral hemorrhagic fevers of South America. Biomédica. 2002;22:287-95.

4. Oyewale T. Yellow fever in Africa: public health impact and prospects for control in the 21st century. Biomédica. 2002;22:178-93.

5. Organización Panamericana de la Salud. II Reunión conjunta de la Red de Vigilancia para Enfermedades Emergentes en el Amazonas y la Región del Cono Sur. Atlanta, Georgia, 2002. Rev Patol Trop. 2003;32(Supl.1):1-152.

6. Zanotto PM, Gould EA, Gao GF, Harvey PH, Holmes EC. Population dynamics of flaviviruses revealed by molecular phylogenies. Proc Natl Acad Sci USA. 1996;93:548-53.

7. Rodríguez G, Velandia M, Boshell J. Fiebre amarilla. La enfermedad y su control. Bogotá: Instituto Nacional de Salud; 2003. p. 47.

8. Monath TP, Ballinger ME, Miller BR, Salaun JJ. Detection of yellow fever viral RNA by nucleic acid hybridization and viral antigen by immunocytochemistry in fixed human liver. Am J Trop Med Hyg. 1989;40:663-8.
9. Ricaurte O, Sarmiento L, Caldas ML, Rodríguez G. Evaluación de un método inmunohistoquímico para el diagnóstico de la fiebre amarilla. Biomédica. 1993;13:15-9.

10. Deubel V, Huerre M, Cathomas G, Drouet MT, Wuscher N, LeGuenno B, et al. Molecular detection and characterization of yellow fever virus in blood and liver specimens of a nonvaccinated fatal human case. J Med Virol. 1997;53:212-7.

11. Pierre V, Drouet MT, Deubel V. Identification of mosquitoborne flavivirus sequences using universal primers and reverse transcription/polymerase chain reaction. Res Virol. 1994;145:93-104.

12. Méndez J, Rodríguez G, Bernal MP, Calvache D, Boshell J. Detección molecular del virus de la fiebre amarilla en muestras de suero de casos fatales humanos y en cerebros de ratón. Biomédica. 2003;23:232-8.

13. Monath TP. Yellow fever: Victor, Victoria? Conqueror, Conquest? Epidemics and research in the last forty years prospects for the future. Am J Trop Med Hyg. 1991;45:1-43.

14. Monath TP. Flaviviruses. En: Field's Virology. Second Edition. New York: Raven Press Ltd; 1990.

15. Groot H, Boshell J. Dengue, dengue hemorrágico y fiebre amarilla. En: Chalem F, Escandón J, Campos J, Esguerra R, editores. Medicina Interna. Tercera edición. Bogotá: Fundación Instituto de Reumatología e Inmunología; 1997. p. 645-51.

16. Tesh RE. A method for the isolation and identification of dengue virus using mosquito cell cultures. Am J Trop Med. 1979;28:1053.

17. Monath TP, Cropp CB, Muth DJ, Calisher CH. Indirect fluorescent test for the diagnosis of yellow fever. Trans $\mathrm{R}$ Soc Trop Med Hyg. 1981;75:282-6.

18. Martin DA, Muth DA, Brown T, Johnson AJ, Karabatsos N, Roehrig JT. Standardization if immunoglobulin M capture enzyme-linked immunosorbent assays for routine diagnosis of arboviral infections. J Clin Microbiol. 2000;38:1823-6.

19. Beaty BJ, Calisher CH, Shope RE. Arboviruses. In: Lennette EH, Lennette, DA, Lennette ET, editors. Diagnosis procedures for viral, rickettsial and chlamydial infections. Seventh edition. Washington, D.C.: American Public Health Association; 1995. p. 204-5.

20. Calisher $\mathbf{C H}$, Meurman O, Brummer-Korvenkontio $\mathbf{M}$, Halonen PE, Muth DJ. Sensitive enzyme immunoassay for detecting immunoglobulin $M$ antibodies to Sinbdis virus and further evidence that Pogosta disease is caused by a Western equine encephalitis complex virus. J Clin Microbiol. 1985;22:566-71.

21. Monath TP, Nystrom RR. Detection of yellow fever virus in serum by enzyme immunoassay. Am J Trop Med Hyg. 1984;33:151-7.

22. Méndez J, Parra E, Neira M, Rey GJ. Detección por reacción en cadena de la polimerasa de transcriptasa reversa del virus de la fiebre amarilla en monos silvestres: una herramienta sensible para la vigilancia epidemiológica. Biomédica. 2007;27:461-7.

23. Benenson AS. Paludismo (Malaria). En: Manual para el control de las enfermedades transmisibles. Decimosexta edición. Publicación Científica No. 564. Washington, D.C.: Organización Panamericana de la Salud; 1997. p. 350-9. 